Bradish, C. J., Henderson, W. M. \& Kirkham, J. B. (1960). J. gen. Microbiol. 22, 379-391

\title{
Concentration and Electron Microscopy of the Characteristic Particle of Foot-and-Mouth Disease
}

\author{
By C. J. BRADISH, W. M. HENDERSON* AND J. B. KIRKHAM \\ Research Institute (Animal Virus Diseases), Pirbright, Surrey
}

\begin{abstract}
SUMMARY: The infective component of the virus system of foot-and-mouth disease was concentrated and purified by ultracentrifugation and solvent extraction. Infective materials derived from ox, guinea-pig, mouse, chicken, goose and tissue culture were employed. The infective concentrates (D-fractions) and the separated smaller complement-fixing components (U-fractions) were characterized by infectivity, complement-fixing activity and nitrogen content. The D-fractions, of activity up to $10^{14 \cdot 5} \mathrm{ID} \mathrm{50/g}$. N, represented less than $0.1 \%$ of the initial protein content. Electron micrographs of the D-fractions showed clusters and hexagonal arrays of 2.5 to $27 \mathrm{~m} \mu$ 'spherical' particles of granular structure. These defined fractions of the virus system were used in a number of subsequent investigations.
\end{abstract}

It has been shown (Bradish, Brooksby, Dillon \& Norambuena, 1952) that by ultracentrifugal procedures the virus system of foot-and-mouth disease, as recovered from a number of hosts, may be separated into two major components of sedimentation coefficients about 70 and 8 Svedberg units, respectively. These correspond with particle diameters of about 20 and $7 \mathrm{~m} \mu$. The first of these, the infective component, is associated with about half of the initial complement-fixing activity of the system. The smaller component contributes the remainder of the complement-fixing activity of the system and, if infective, less than $0.01 \%$ of the initial infectivity. The antibody-combining properties of these components are described in the following papers (Bradish, Brooksby \& Tsubahara, 1960; Bradish \& Brooksby, 1960).

In the present study concentrates of the infective component were examined under the electron microscope and the particles observed were characterized physically and biologically. Previous electron microscope studies by von Ardenne \& Pyl (1940) and Bernard, Girard, Hirtz, Mackowiak \& Lorrin (1949) failed to reveal discrete characteristic particles. Discrete spherical particles of 22-28 $\mathrm{m} \mu$ diameter have since been demonstrated in infective concentrates derived from tissue culture materials (Bachrach \& Breese, 1958) and from a variety of tissues and vesicular fluids (present authors quoted by Brooksby, 1958).

\section{METHODS}

Sources of infective material. Virus was obtained from the characteristic lesions produced by the intradermal inoculation of the plantar pads of guinea pigs or the tongues of cattle. Vesicular fluid was collected 18-24 hr. after inoculation and was immediately diluted 2 to 20 times in a phosphate buffer

* Present address : Pan American Foot-and-Mouth Disease Center, Caixa Postal 589, Rio de Janeiro, Brazil. 


\section{C. J. Bradish, W. M. Henderson and J. B. Kirkham}

solution $\left(0 \cdot 0348 \mathrm{M}-\mathrm{Na}_{2} \mathrm{HPO}_{4}+0 \cdot 0052 \mathrm{M}-\mathrm{KH}_{2} \mathrm{PO}_{4} ; \mathrm{pH} 7 \cdot 6\right)$. This buffer solution was used for most dilutions and suspensions. Suspensions of vesicular epithelium were prepared by grinding or milling each tissue in phosphate buffer solution (1 g. tissue/6-10 ml. buffer). The supernatant fluid from virus infected cultures of bovine tongue epithelium (Frenkel, 1947) or suspensions of epithelium from such cultures $(25 \mathrm{ml}$. phosphate buffer solution/g. tissue) were also used as sources of infective material.

Other sources were: suspensions of hearts of 14- to 18-day chick embryos dead 3-4 days after intravenous inoculation of virus; suspensions of epithelium of severe local lesions on the tongues of 8-month chickens killed $24 \mathrm{hr}$. after intra-epithelial inoculation of virus; suspensions of hearts and carcasses of unweaned mice severely paralysed or dead 1-2 days after intraperitoneal inoculation of virus. Suspensions containing $1 \mathrm{~g}$. tissue/10 ml. phosphate buffer solution were prepared in each case. A single sample of $0.05 \mathrm{ml}$. vesicular fluid from a lesion on the foot of an infected goose was also used as a source of virus (Skinner, 1959).

Titration of infectivity. Infectivity was estimated by intraperitoneal inoculation of a series of tenfold dilutions into four or five groups of 5 to 10 unweaned mice (Skinner, 1951). The bovine material described in Table 1 was titrated by the multiple inoculation of each sample into the tongues of two steers (Henderson, 1949). The $50 \%$ end-point dilutions were calculated according to Reed \& Muench (1938) and reduced to ID 50/ml. or ID 50/g N.

Estimation of complement-fixing activity. The complement-fixing activity of some concentrates derived from guinea-pig and mouse materials was estimated by the method described by Brooksby (1952); an excess of homotypic guinea-pig hyperimmune serum was used in these tests. Complement-fixation data are discussed in greater detail in the following papers.

Estimation of nitrogen and protein. Nitrogen was determined by the microKjeldahl method (Ma \& Zuazaga, 1942; Markham, 1942) and by the microdiffusion procedure (Conway, 1950). An adaptation of the Nessler colorimetric procedure was also used. Ultraviolet absorption measurements were made with a Beckman Model DU Spectrophotometer with 2 and $10 \mathrm{~mm}$. optical cells.

Electron microscopy. Drops of the preparations to be studied were placed on collodion or carbon films on mounting grids and fixed by exposure to the vapour of a $1 \%$ osmium tetroxide solution for $30 \mathrm{~min}$. in a small sealed chamber. Other procedures are defined in the text. After partial evaporation the drops were removed with capillary pipettes and the specimen films freed from buffer salts by the application and removal of drops of distilled water. The dry specimen films were then examined directly or were shadowed at an angle of $14^{\circ}$ with manganin, chromium or platinum. Specimens were examined in an R.C.A. EMU $2 \mathrm{~B}$ electron microscope fitted with a compensated objective polepiece (Hiller \& Ramberg, 1947) and, in later work, a $50 \mu$ objective aperture. Magnification was determined by the use of Dow polystyrene latex of accepted diameter 2590 Å. (Backus \& Williams, 1948; Scott, 1949). Electron micrographs were taken at magnifications of 8000 to 21,000 . The dimensions of 
characteristic particles or clusters were observed directly from the plates with a travelling microscope providing a $\times 10$ optical magnification.

Concentration of the infective component by ultracentrifugation. The models $\mathbf{E}$ and L Spinco ultracentrifuges (Spinco Division, Beckman Instruments, Inc., Palo Alto, California) were used with a range of angle rotors holding plastic tubes of 8-100 ml. capacity. The special swinging-cup rotor and its micro-cups was used when volumes down to $0 \cdot 1 \mathrm{ml}$. were to be processed (Bradish et al. 1952; Bradish, Brooksby \& Dillon, 1956). Centrifugation processes are defined here and in the following papers in terms of the $G$ unit. This represents the appropriate integration of time and speed of rotation taken over the whole period of acceleration, constant speed and retardation. A period of $1 \mathrm{hr}$. at 10,000 rev./ min. (equivalent to $6750 \mathrm{~g}$ at $6 \mathrm{~cm}$. or $9000 \mathrm{~g}$ at $8 \mathrm{~cm}$., etc.,) defines $1 \mathrm{G}$ unit. One hour at $30,000 \mathrm{rev} . / \mathrm{min} .(81,000 \mathrm{~g}$ at $8 \mathrm{~cm}$., etc. $)$ thus contributes $9 \mathrm{G}$ units. This $\mathrm{G}$ notation permits the expression of the time and speed of rotation as a single number which, unlike the statement in terms of $g$, is a definition of the whole centrifugation process and does not change as the radius of rotation increases. The use of the $\mathrm{G}$ unit is discussed in the above citations.

Before fractionation each starting material was clarified by centrifugation so that $90 \%$ of the initial infectivity was retained by the clear supernatant. The appropriate condition was $0.5 \mathrm{G}$ obtained, for example, by accelerating the Spinco D rotor to $17,500 \mathrm{rev} . / \mathrm{min}$. and retarding immediately at the standard rate, or by maintaining the swinging-cup rotor at $20,000 \mathrm{rev} . / \mathrm{min}$ for $6 \mathrm{~min}$.

Analyses of the nitrogen content of clarified starting materials showed that undiluted guinea-pig pad vesicular fluid contained about $5 \mathrm{mg} . \mathrm{N} / \mathrm{ml}$., vesicular fluid from lesions on bovine tongue 6-12 $\mathrm{mg}$. $\mathrm{N} / \mathrm{ml}$. and supernatant fluid from infected cultures of bovine tongue epithelium about $0 \cdot 4 \mathrm{mg} . \mathrm{N} / \mathrm{ml}$. Clarified starting materials derived from tissue suspensions contained about $\mathbf{0} \cdot \mathbf{7} \mathrm{mg}$. $\mathrm{N} / \mathrm{g}$. tissue suspended.

The clarified starting material was next centrifuged to sediment the infective component (the condition adopted was that which would just deposit a component of sedimentation coefficient equal to half that of the infective component). The appropriate condition was about $12 \mathrm{G}(3 \mathrm{hr}$. at $20,000 \mathrm{rev} . / \mathrm{min}$., $54 \mathrm{~min}$. at $45,000 \mathrm{rev} . / \mathrm{min}$., etc.) and was determined by the choice of rotor and the volume loaded per tube. At the conclusion of the first sedimentation the total supernatant fluids were removed with a capillary pipette and the 1-6 mm. diam. transparent gelatinous deposits resuspended in $1 / 10$ to $1 / 20$ of the initial volume of phosphate buffer solution. The deposits were resuspended by agitation for $c .1 \mathrm{~min}$. in the bore of a fine capillary pipette, followed by overnight rotation in an inclined bottle at $4^{\circ}$. The turbid resuspension obtained at this stage was clarified as before by centrifugation at $0.5 \mathrm{G}$ and carried forward immediately to a second cycle of deposition at $12 \mathrm{G}$. The second-cycle deposits of the infective component were resuspended and clarified as in the first cycle to produce the second cycle concentrate. The volume of this concentrate, called the D-fraction of the virus system, was usually $0.5-5 \mathrm{ml}$. according to the nature of subsequent experiments.

The U-fraction of the virus system was obtained (Bradish et al. 1952) from 


\section{C. J. Bradish, W. M. Henderson and J. B. Kirkham}

the upper supernatant fluid of the first $12 \mathrm{G}$ centrifugation by running this again at $12 \mathrm{G}$ and retaining the upper two-thirds of the supernatant fluid. In both cycles this supernatant volume was sampled by the aid of a fine capillary pipette with upturned tip.

The overall concentration factor of the D-fraction, expressed as the ratio of the initial to the final volume, ranged from 1 to 2000 according to the volume of starting material available. Tissue culture materials provided the highest initial volumes but guinea-pig, bovine and goose vesicular fluids the highest initial infectivities. The high infectivity of the vesicular fluids more than compensated for their limited volumes and they were the preferred starting materials.

\section{RESULTS}

\section{Recovery of the infective component in concentrates}

Table 1 shows the results obtained in typical experiments with different starting materials. Within the limits of error of the infectivity test, the average recovery of infectivity was about $40 \%$ in the second-cycle deposit resuspensions (D-fraction). Thus about $60 \%$ of the initial infectivity was recovered in each cycle of deposition, resuspension and clarification. Similar recovery data were obtained by Bachrach \& Breese (1958) and in studies of the infective component of vesicular stomatitis (Bradish et al. 1956).

Concentrates of the infective component derived from guinea-pig materials contained about $14 \%$ of the complement-fixing activity of the clarified starting materials. With allowance made for the approximately equal partition of complement-fixing activity between the infective component and the smaller antibody-combining component, this indicates a recovery of the infective component, based only on complement-fixation data, of at least $30 \%$ and compares closely with the estimate based only on infectivity data. A 100-fold concentrate of the infective component is associated with a complement-fixing activity about $\mathbf{3 0}$ times greater than that of the clarified starting material.

To eliminate the arbitrary concentration factor, the 'purity' or 'specific activity' of concentrates is expressed by the ratio of the concentration of a specific marker to that of a non-specific marker. These marker ratios have been those of infectivity (ID 50/ml.) or specific complement-fixing activity ( $\mu \mathrm{l}$. complement as guinea-pig serum $/ \mathrm{ml}$.) to nitrogen content (g. $\mathrm{N} / \mathrm{ml}$.). Table 2 shows how these criteria of separation improved during concentration.

The ratio of infectivity to nitrogen content was improved from about $10^{10}-10^{11}$ ID 50/g. $\mathrm{N}$ in the clarified starting materials to $10^{13 \cdot 5}-10^{14 \cdot 5} \mathrm{ID} \mathrm{50/g}$. $\mathbf{N}$ in the final concentrates from vesicular fluids. These data imply an improvement in 'purity' of at least 1000-fold as expressed by elimination of nitrogenous material. Similar final activities were obtained in earlier studies of the infective component in vesicular stomatitis (Bradish et al. 1956). Schwerdt \& Schaffer (1956) reported a comparable activity of $2 \times 10^{13}$ plaque-forming units/ g. protein for their concentrates of poliomyelitis virus.

Theoretically, maximum activities of the order $10^{18} \mathrm{ID} 50 / \mathrm{g}$. $\mathrm{N}$ should be observed if each characteristic particle of $25 \mathrm{~m} \mu$ diameter initiates infection 

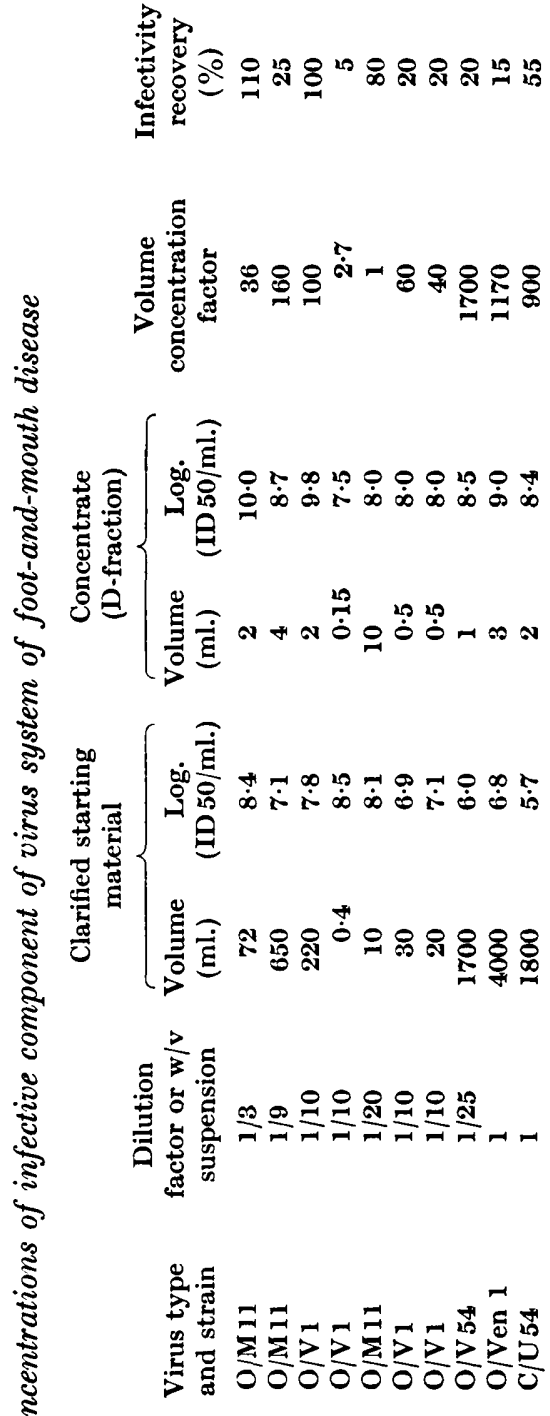



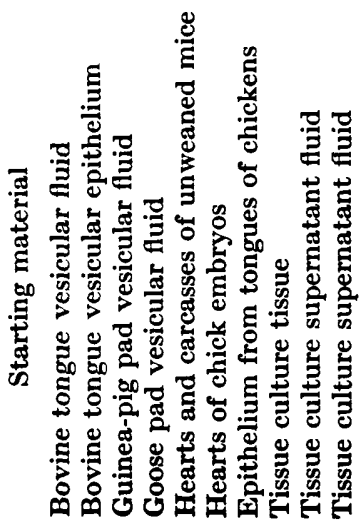




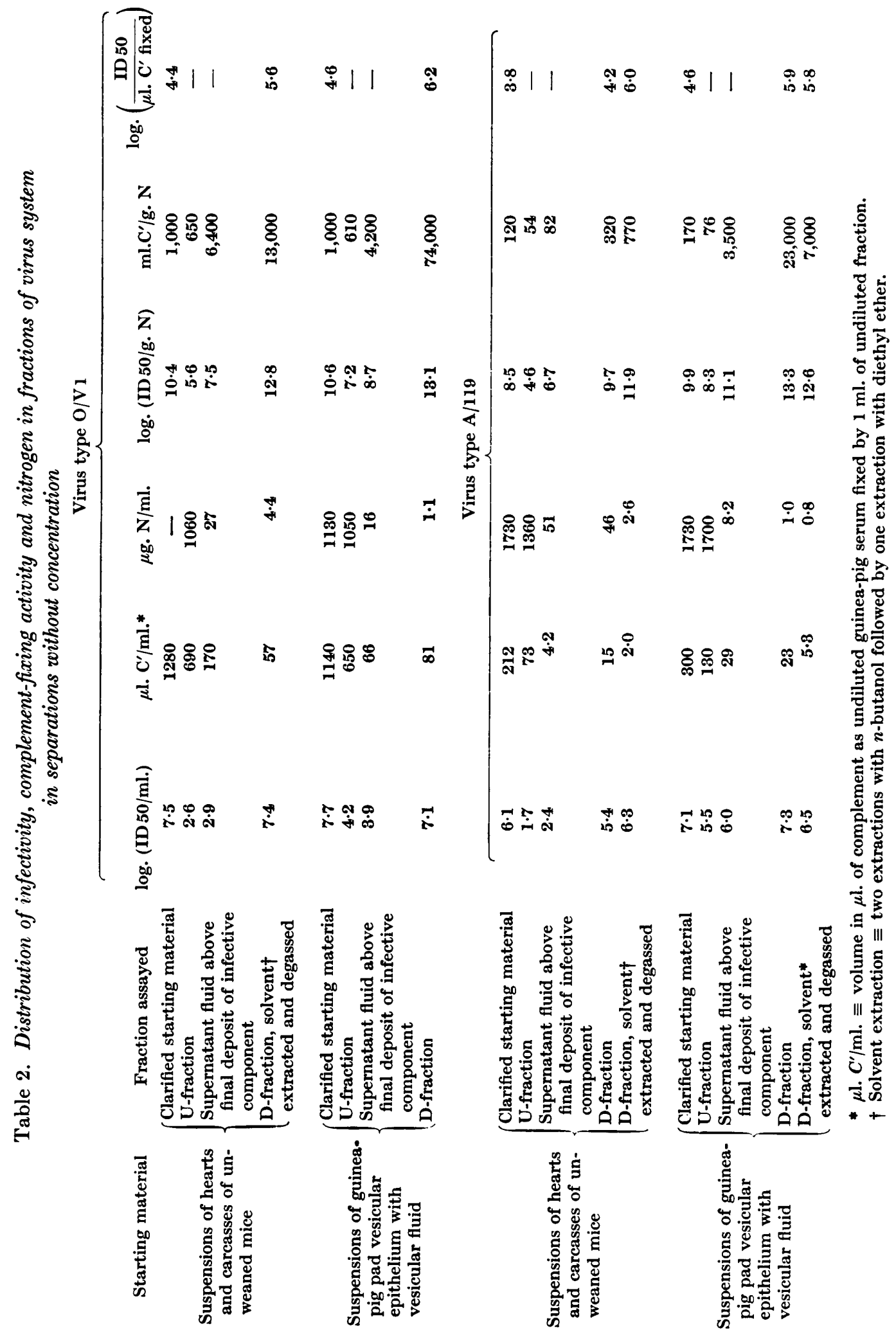


and if extraneous nitrogen is negligible. This activity is about 1000 times greater than that observed for the best concentrates and indicates that in these preparations each infective particle was accompanied by a much greater mass of non-infective particles and inactive non-viral material. Bachrach $\&$ Breese (1958) observed particle/plaque ratios of $30-1600$ in their studies in infective concentrates derived from bovine-kidney cultures.

Solvent extraction. To decrease further the content of inactive material, concentrates of infective component derived from suspensions of the tissues of infected mice or chicks were extracted 2 to 3 times with equal volumes of $n$-butanol or diethyl ether. Mixtures were shaken for $10 \mathrm{~min}$. at room temperature before separation by centrifugation. The clear aqueous layers were withdrawn from below the intermediate gel layers. Final extractions were made with ether followed by degassing under reduced pressure. With these concentrates, containing initially up to $50 \mu \mathrm{g}$. $\mathrm{N} / \mathrm{ml}$., solvent extraction decreased the nitrogen content by at least $75 \%$ with less than $20 \%$ loss of infectivity at each extraction. Concentrates which were initially grossly opalescent became water clear after extraction. Concentrates of the infective component were thus obtained containing 2-10 $\mu \mathrm{g}$. N/ml. for infectivities of $10^{8} \mathrm{ID} \mathrm{50} / \mathrm{ml}$., corresponding with activities of up to $10^{13} \mathrm{ID} \mathrm{50} / \mathrm{g}$. N (Table 2). These activities approach those obtained for concentrates derived from guineapig and bovine sources but are still far below the ideal maximum activity of about $10^{18}$ ID 50/g. N. Solvent extraction did not improve the purity of concentrates of infective component derived from guinea-pig vesicular fluids or pad suspensions.

Ultraviolet absorption and other control data. A number of non-infective or 'normal' vesicular fluids and tissue suspensions were taken through the concentration procedure in parallel with infective materials. 'Normal' vesicular fluid and vesicular epithelium were obtained from bovine tongue and guineapig pad by scalding these sites with boiling water while the animals were anaesthetized. The animals were killed before recovery. Suspensions and dilutions were then prepared as for the infective materials. Similar 'normal' suspensions were prepared from chick and mouse tissues from animals of the same age as those infected. In some instances the 'normal' animals were injected with saline or phosphate buffer to simulate the operation of infection. No control is, however, entirely adequate since virus invasion and multiplication may liberate elements of the cellular and the virus systems which are not recognized as components of either of these. For electron microscopy the most satisfactory 'control concentrate' is probably that obtained from the appropriate host following infection with a recognizably distinct virus, producing similar pathological changes, such as vesicular stomatitis, for this study.

'Control' and infective concentrates were studied in parallel by ultraviolet (u.v.) spectroscopy, nitrogen assay and electron microscopy. Although the infective concentrates were readily distinguished in electron microscopy by the observation of characteristic $25 \mathrm{~m} \mu$ particles, the u.v. absorption curves and nitrogen contents of the control and infective concentrates were not significantly different. Both control and infective concentrates were obtained with 


\section{C. J. Bradish, W. M. Henderson and J. B. Kirkham}

$260 \mathrm{~m} \mu / 280 \mathrm{~m} \mu$ absorption ratios of up to 1.7 ; a figure which might otherwise have been regarded as an indication of virus nucleoprotein. These data indicate that the concentrates derived from the vesicular fluids contained a high proportion of contaminating material of host origin, despite their high activity and the clean appearance of the electron micrographs.

\section{The physical particle}

The electron micrographs (Pls. 1, 2) show significant numbers of discrete particles and clusters in infective concentrates derived from different hosts and tissues (Table 1). Vesicular fluids derived from steer, guinea pig and goose were the most satisfactory starting materials since their concentrates showed the highest activities (c. $10^{14} \mathrm{ID} \mathrm{50/g.} \mathrm{N)}$ and the greatest number of intact particles and regular arrays.

The average diameter of unshadowed particles was $20 \cdot 7 \pm 2 \cdot 2 \mathrm{~m} \mu$; this is 4-5 $\mathrm{m} \mu$ less than that for lightly shadowed particles. In view of uncertainty in the estimation of the diameter of an unshadowed particle of low contrast and ill-defined limits, or of the diameter of a shadowed and enlarged particle, the centre-centre separation in clusters and linear arrays of particles was analysed. The centre-centre separation is equivalent to the effective particle diameter if the clusters are tight-packed but not compressed. Measurements were made of the distances between the centres of the extreme particles in well-defined linear arrays containing 4 to 11 particles. A total of 250 such arrays containing in all 1200 particles were measured and indicated a mean centre-centre separation of 24.5-25.0 $\mathrm{m} \mu$. The data contributing to this result relate to air-dried particles from guinea-pig, bovine and goose vesicular fluids.

This mean centre-centre separation of $25 \mathrm{~m} \mu$ is $4 \mathrm{~m} \mu$ greater than the mean diameter of unshadowed particles and about $0.5 \mathrm{~m} \mu$ less than the mean diameter observed for lightly shadowed particles. The clusters (Pl. 1, figs. 4, 6) show the apparent non-contact of unshadowed particles.

Bachrach \& Breese (1958) found $28 \mathrm{~m} \mu$ for the width of the uranium shadowed particle and $22 \mathrm{~m} \mu$ for the minimum diameter of the clustered particle. These dimensions may not correspond exactly with those for particles which have been freeze-dried or otherwise mounted.

Interpretation of micrographs of the physical particle. The images of discrete particles were frequently angular and some particles appeared as clusters of smaller granules (Pl. 1, fig. 5). Clusters of particles appeared as regular hexagonal arrays which indicated their dimensional uniformity (Pl. 1, fig. 4; Pl. 2, fig. 9). To demonstrate these features more clearly, concentrates of infective component were examined after 'staining' by phosphotungstic acid, uranyl acetate or phosphomolybdic acid (Valentine \& Hopper, 1957; Horne, Brenner, Waterson \& Wildy, 1959; Brenner \& Horne, 1959). The most satisfactory results were obtained by mixing the virus sample with an equal volume of $0.1 \%(w / v)$ solution of the 'stain' previously adjusted to $\mathrm{pH} 7$ or 8 in the appropriate buffer. The mixtures were held at room temperature for $10 \mathrm{~min}$. before mounting for electron microscopy. Similar micrographs were obtained after each of these treatments $(\mathrm{Pl} .3,4)$. The characteristic particles appeared 
as irregular clusters of small granules within a ring of higher contrast. The ring profile was frequently angular even for single particles outside the regular hexagonal arrays (Pl. 3, fig. 13). Stained and freeze-dried preparations showed similar particles with peripheral rings of low density (Pl. 4, fig. 15). The density of the peripheral rings appears to be related to the presence of protein in the background of the micrographs since the rings were less dense or broken in regions where this protein was absent (Pl. 3, fig. 13). Measurements on about 1000 single or clustered particles in different stained preparations showed the mean diameter to be $27 \pm 1 \mathrm{~m} \mu$.

The identification of the physical particle. In addition to the regular observation of the $25 \mathrm{~m} \mu$ particle in infective concentrates derived from different hosts and tissues, control experiments were made to relate this physical particle to the infective component. In the first of these a suspension was prepared from pad epithelium of guinea-pigs which had failed to react to inoculation with a high dilution of virus in an infectivity titration. This suspension of epithelium was concentrated 24-fold as for the recovery of infective component, but no particles were observed. Similar 'concentrates' derived from fluid or epithelium raised by scalding bovine tongue or guinea-pig pad, or directly from bovine or guinea-pig serum, contained no characteristic particles of the type described above.

A less negative test for the identity of the physical particle was made by concentrating infective component from starting materials previously mixed with appropriate dilutions of inactivated homotypic or heterotypic guinea-pig hyperimmune serum. Vesicular fluid from lesions on bovine tongue was diluted $1 / 10$ to $1 / 40$ in dilutions of antiserum and allowed to stand for $2 \mathrm{hr}$. at room temperature with occasional shaking. The mixtures were then clarified as for other starting materials and samples removed for infectivity control. The remaining volumes were carried forward as in the standard procedure for the concentration of infective component. The infectivity titres of clarified mixtures of bovine vesicular fluid with 1/10 dilutions of homotypic antiserum were at least $4 \mathrm{log}$. units lower than those observed for mixtures with heterotypic antiserum, normal serum or phosphate buffer solution. When 1/100 dilutions of homotypic antiserum were used the infectivity titres were lowered by about $2.5 \mathrm{log}$. units. The infectivity titres of the derived concentrates, with allowance made for volume concentration factors, corresponded with those of the initial virus-serum mixtures. Mixture with heterotypic or normal serum did not interfere with the recovery of infectivity in any way.

Micrographs of infective concentrates obtained from mixtures of vesicular fluid with normal or heterotypic serum showed particles and clusters of $25 \mathrm{~m} \mu$ particles (Pl. 2, fig. 9) which were identical in appearance to those previously obtained from vesicular fluid alone (Pl. 1, fig. 2). Micrographs of concentrates from mixtures of vesicular fluid with homotypic antiserum showed neither characteristic particles nor gross aggregates and clusters. This result supports the identification of the $25 \mathrm{~m} \mu$ particle with the infective component. Bachrach \& Breese (1958) identified the physical particle with the infective component by distinguishing the clumps which appeared in the presence of specific 


\section{C. J. Bradish, W. M. Henderson and J. B. Kirkham}

antiserum from those which occurred in the presence and absence of normal serum.

In other experiments infective concentrates were examined before and after inactivation by heating at $40-56^{\circ}$ for up to $1 \mathrm{hr}$. The initially infective material showed characteristic particles which were replaced in the thermally inactivated material by particulate aggregates and strings (Pl. 2, fig. 10). This demonstrates again the correlation of the characteristic physical particle with the infective component. The thermal degradation of the infective $25 \mathrm{~m} \mu$ component is discussed more fully in a following paper (Bradish \& Brooksby, 1960). The observed diameter of the physical particle is in accord with the sedimentation properties of the infective component (see Discussion), thus supporting again the conclusion that the physical particle is derived from the infective component.

\section{DISCUSSION}

A number of investigators have obtained data from which the diameter of the infective component of foot-and-mouth disease may be estimated. Analysis in terms of the infectivity or antibody-combining capacity of centrifuge samples (Elford \& Galloway, 1937; Schlesinger \& Galloway, 1937; Bradish et al. 1952) indicate sedimentation coefficients between 40 and 90 Svedberg units with a probable minimum value of 70 Svedberg units. These methods are limited by the accuracy of their titration procedures. Optical analytical estimates for the sedimentation coefficient range from 20 Svedberg units by Jannsen (1941) to 140 Svedberg units by Bachrach (1952), Randrup (1952) and Wehmeyer (1957). These data were reviewed by Röhrer \& Pyl (1958). Of these extreme estimates the higher one now seems more probable, but the relationship between the sedimentation boundary and the infective component was rarely established. The protein concentrations of the samples analysed were sufficiently high in relation to their infectivity to suggest that only a very small proportion of the sedimenting material was related to the infective component. The present investigation indicates a particle diameter near $25 \mathrm{~m} \mu$ for the infective component. This corresponds with sedimentation coefficients of 149,116 and 87 Svedberg units for partial specific volumes of $0 \cdot 700,0.750$ and $0 \cdot 800$, respectively; the latter values are assumed for typical protein-nucleoprotein macromolecules. More precisely controlled investigations, particularly of the sedimentation properties in relation to infectivity, are required to resolve these uncertainties.

In the present experiments, despite the relatively small loss of infectivity. during concentration, probably very few of the observed particles were infective even in the initial vesicular fluids. The recovery data for the more active concentrates indicate, in terms of infectivity and nitrogen content, that of every 1000 characteristic particles at least 4 were infective in the vesicular fluid and two in the derived concentrate.

The problem of the distribution of the active and inactive states of the characteristic particle and its fragments in relation to the associated biological activities of the sample may be resolved in part by direct counting and micro- 
analytical procedures. The observation of granules as elements in the structure of the characteristic particle is of particular interest in view of the demonstration by complement-fixation studies of a $7 \mathrm{~m} \mu$ antibody-combining component in the initial infective materials (Bradish et al. 1952), and in thermally-degraded concentrates of infective component. This is discussed in the following papers. It seems probable that the specific antibody-combining component derived from the virus particle of foot-and-mouth disease is a $7 \mathrm{~m} \mu$ protein subunit of the type demonstrated at the surface of polyhedral virus particles by highresolution electron microscopy (Horne et al. 1959) and X-ray analysis (Caspar, 1956; Klug, Finch \& Franklin, 1957).

The authors are indebted to their colleagues for their ready co-operation. Particular thanks are due to Mrs J. O. Farley, Dr J. B. Brooksby, Mr A. W. Morrow, Mr T. W. F. Pay, Dr H. S. Sharpe and Mr H. H. Skinner for the supply and titration of certain infective materials, to $\mathrm{Mr} \mathrm{E}$. Adams for Kjeldahl and other analyses and to $\mathrm{Mr} \mathbf{T}$. Burrows and Miss $\mathbf{H}$. Wigman for assistance in ultracentrifugal and photographic procedures.

\section{REFERENCES}

Ardenne, N. von \& Pyl, G. (1940). Versuche zur Abbildung des Maul- und Klauenseuchevirus mit dem Universal-Elektronenmikroskop. Naturw. 28, 531.

BACHRACH, H. L. (1952). The determination of the sedimentation constant of a homogenous component having the characteristics of the foot-and-mouth disease virus. Amer. J. vet. Res. 13, 13.

Bachrach, H. L. \& Breese, S. S. (1958). Purification and electron microscopy of foot-and-mouth disease virus. Proc. Soc. exp. Biol., N.Y. 97, 659.

Backus, R. C. \& Williams, R. C. (1948). Some uses of uniform sized spherical particles. J. appl. Phys. 19, 1186.

Bernard, R., Girard, H., Hirtz, J., Mackowiak, C. \& Lorrin, R. (1949). Observation du virus de la fièvre aphteuse au microscope electronique. C.R. Acad. Sci., Paris, 229, 1272.

Bradish, C. J. \& Brooksby, J. B. (1960). Complement-fixation studies of the specificity of the interactions between components of the virus system of footand-mouth disease and its antibodies. J. gen. Microbiol. 22, 405.

Bradish, C. J., Brooksby, J. B. \& Dillon, J. F. (1956). Biophysical studies of the virus of vesicular stomatitis. J. gen. Microbiol. 14, 290.

Bradish, C. J., Brooksby, J. B., Dillon, J. F. \& Norambuena, M. (1952). Ultracentrifugal studies of the infective and complement-fixing components in the virus system of foot-and-mouth disease. Proc. roy. Soc. B, 140, 107.

Bradish, C. J., Brooksby, J. B. \& Tsubahara, H. (1960). The complement-fixation test in studies of the components of the virus system of foot-and-mouth disease and its antibodies. J. gen. Microbiol. 22, 392.

Brenner, S. \& Horne, R. W. (1959). A negative staining method for high resolution electron microscopy of viruses. Biochim. biophys. Acta, 34, 103.

BrooksBy, J. B. (1952). The technique of complement-fixation in foot-and-mouth disease research. A.R.C. Rep. Ser. no. 12.

Brooksby, J. B. (1958). The virus of foot-and-mouth disease. Advanc. Virus Res. 5,1 .

CASPar, D. L. D. (1956). Structure of bushy stunt virus. Nature, Lond. 177, 475.

Conway, E. J. (1950). Microdiffusion Analysis and Volumetric Error. London: Crosby, Lockwood and Son Ltd.

Elford, W. J. \& Galloway, I. A. (1937). Centrifugation studies. III. The viruses of foot-and-mouth disease and vesicular stomatitis. Brit. J. exp. Path. 18, 155. 


\section{C. J. Bradish, W. M. Henderson and J. B. Kirkham}

Frenkel, H. S. (1947). La culture du virus de la fièvre aphteuse sur l'epithelium de la langue des bovides. Bull. Off. int. Épizoot. 28, 155.

Henderson, W. M. (1949). The quantitative study of foot-and-mouth disease virus. A.R.C. Rep. Ser. no. 8.

Hillier, J. \& Ramberg, E. G. (1947). Magnetic electron microscope objective; contour phenomena and the attainment of high resolving power. J. appl. Phys. $18,48$.

Horne, R. W., Brenner, S., Waterson, A. P. \& Wildy, P. (1959). The icosahedral form of adenovirus. J. mol. Biol. $1,84$.

Janssen, L. W. (1941). Centrifugation and sedimentation constant of foot-andmouth disease virus protein. Naturw. 29, 102.

Klug, A., Finch, J. T. \& Franklin, Rosalind E. (1957). The structure of turnip yellow mosaic virus: X-ray diffraction studies. Biochim. biophys. Acta, 25, 242.

MA, T. S. \& ZUAZAGA, G. (1942). Micro-Kjeldahl determination of nitrogen. Industr. Engng Chem. (Anal.), 14, 280.

Markiam, R. (1942). A steam distillation micro-Kjeldahl apparatus. Biochem. $J$. $36,790$.

RANDRUP, A. (1952). Ultracentrifugation of the virus of foot-and-mouth disease. I. Experiments for the determination of the sedimentation constant of the virus. Acta path. microbiol. scand. 31, 385.

RANDRUP, A. (1952). Ultracentrifugation of the virus of foot-and-mouth disease. II. Studies on the complement fixing antigen. Acta path. microbiol. scand. 31, 402.

Reed, L. 'T. \& Muench, H. (1938). A simple method of estimating 50 per cent endpoints. Amer. J. Hyg. 27, 493.

Röhrer, H. \& Pyı, G. (1958). Das Maul- und Klauenseuchevirus. In Handbuch der Virusforschung, 4, 379.

Schlesinger, M. \& Galloway, I. A. (1937). Sedimentation of the virus of foot-andmouth disease in the Sharples-Super centrifuge. J. Hyg., Camb. 37, 445.

Schwerdt, C. E. \& Schafrer, F. L. (1956). Purification of poliomyelitis virus propagated in tissue culture. Virology, $2,665$.

Scotr, G. D. (1949). Spherical particles for electron microscopy. J. appl. Phys. 20, 417.

Skinner, H. H. (1951). Propagation of strains of foot-and-mouth disease in unweaned white mice. Proc. R. Soc. Med. 44, 1041.

SkinNER, H. H. (1959). The propagation of the virus of foot-and-mouth disease in domestic poultry. Arch. ges. Virusforsch. 9, 92.

Valentine, R. C. \& Hopper, P. K. (1957). Polyhedral shape of adenovirus particles as shown by electron microscopy. Nature, Lond. 160, 928.

WeHMEYER, P. (1957). Experimental examination of complexes with foot-andmouth disease virus. Acta path. microbiol. scand. 40, 143.

\section{EXPLANATION OF PLATES}

Plates 1 and 2

Virus concentrates mounted at dilutions containing $10^{7}$ to $10^{8}$ mouse ID 50/ml. Magnification to print, $\times 40,000$ except in fig. $3(\times 19,000)$, fig. $4(\times 95,000)$ and fig. $5(110,000)$.

Fig. 1. Virus of type Vallée $O / 1$ from goose pad vesicular fluid, shadow cast with manganin.

Fig. 2. Virus of type Vallée O/M. 11 from bovine tongue vesicular fluid, shadow cast with manganin.

Fig. 3. Virus of type S.A.T. 1/R.V. 11 from mouse pancreas in spray droplet with latex particle and $1 / 10^{\circ}$ rabbit serum, shadow cast with manganin.

Figs. 4, 6. Virus of type Waldman C/GC from guinea-pig pad vesicular fluid and epithelium, not shadow cast.

Fig. 5. Virus of type Vallee $O / 1$ from guinea-pig pad vesicular fluid and epithelium, shadow cast with chromium. 
Journal of General Microbiology, Vol. 22, No. 2
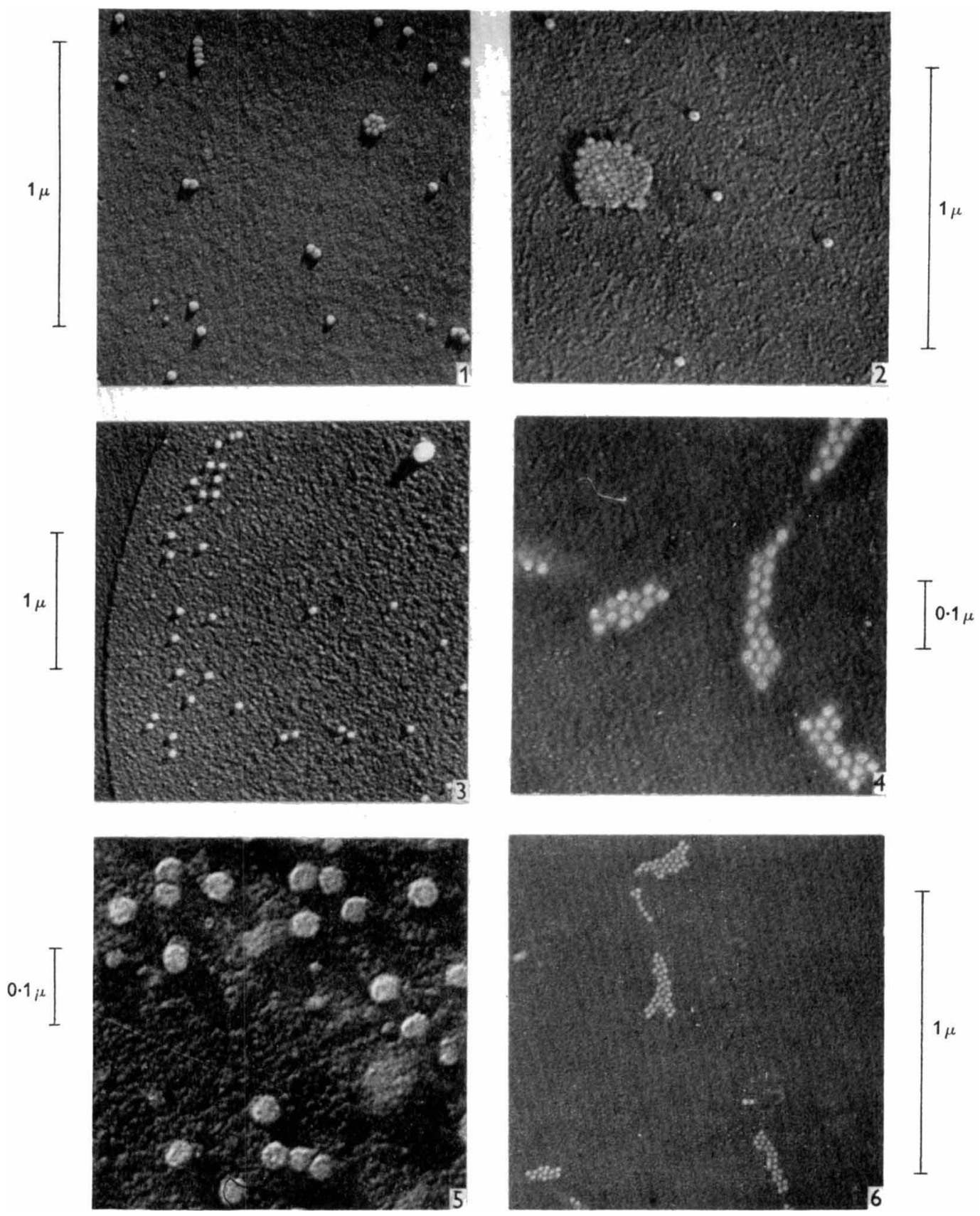

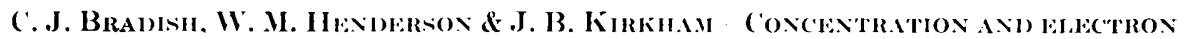

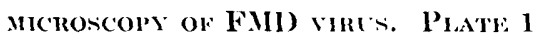

(Facing p. 390)) 
Journal of General Microbiology, Vol. 22, No. 2
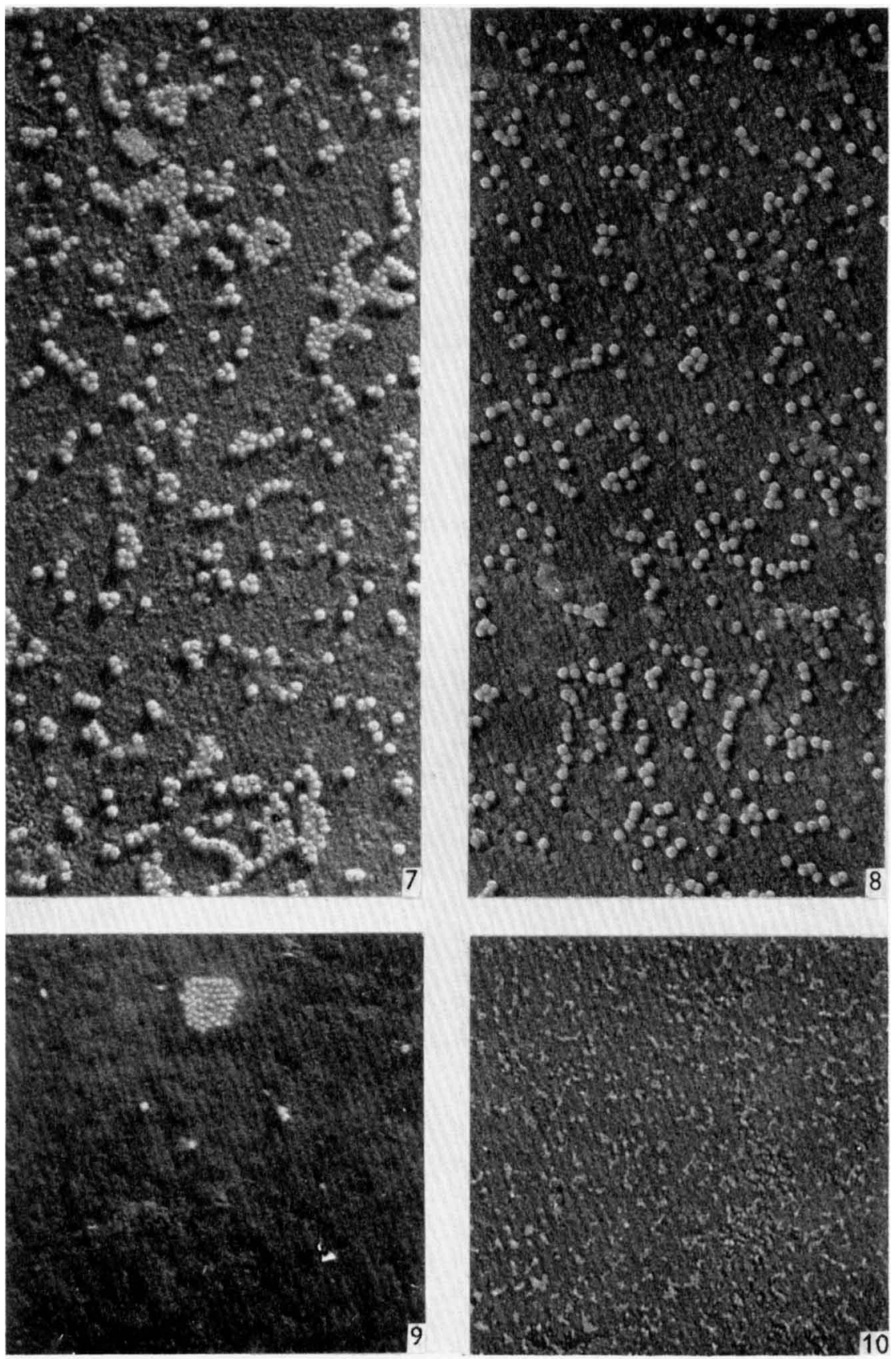

$1 \mu$

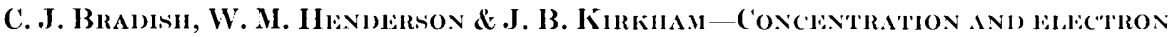
MICROSCOPY OF FMD viRUS. P'LATE? 
Jourmal of General Wicrobiology, Vol. 22, No. 2
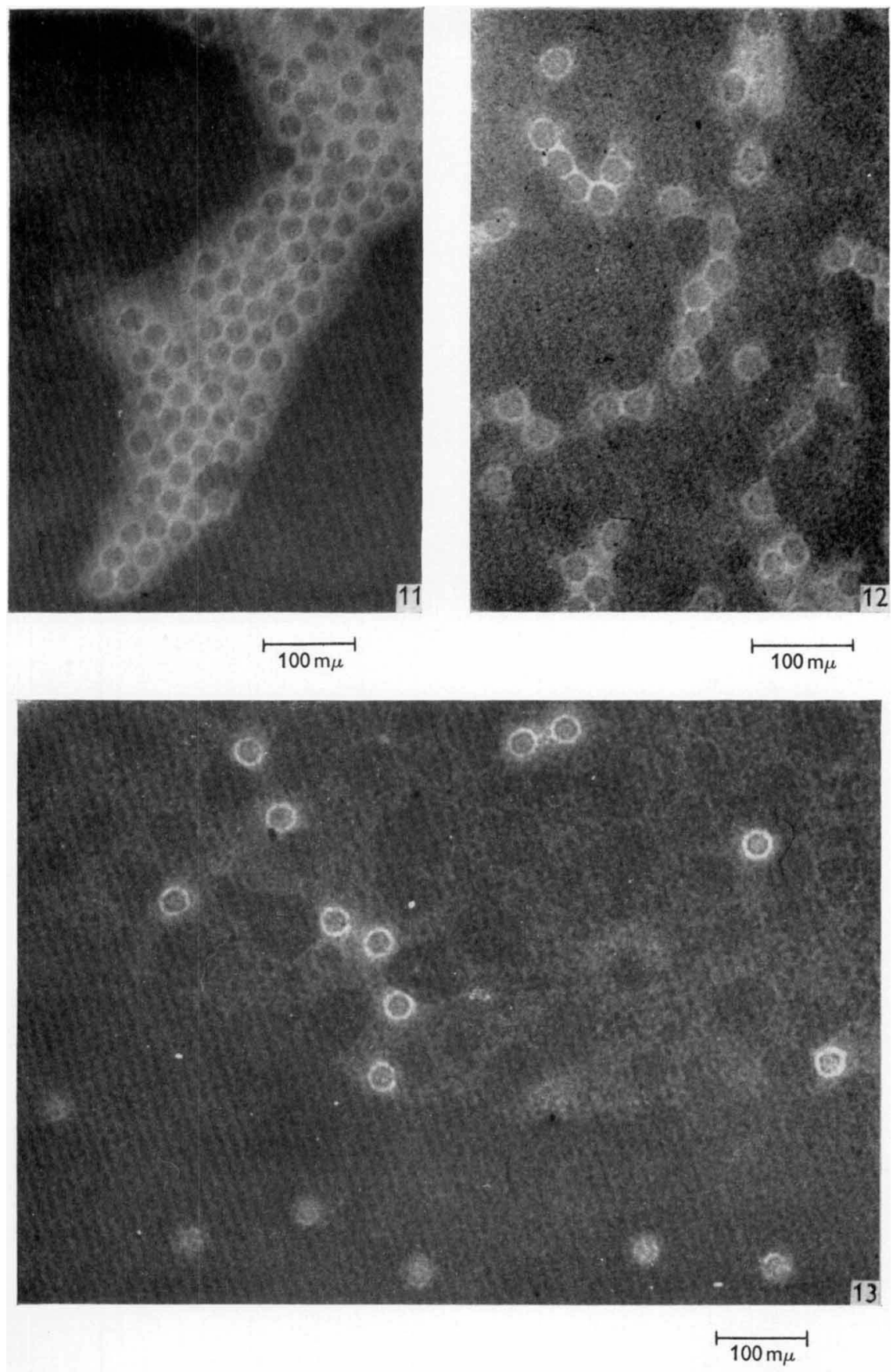

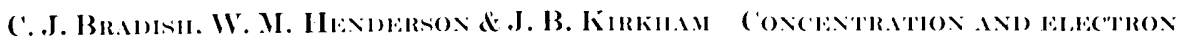

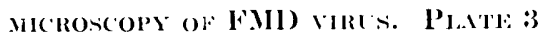


Journal of General Microbiology, Vol. 22, No. 2
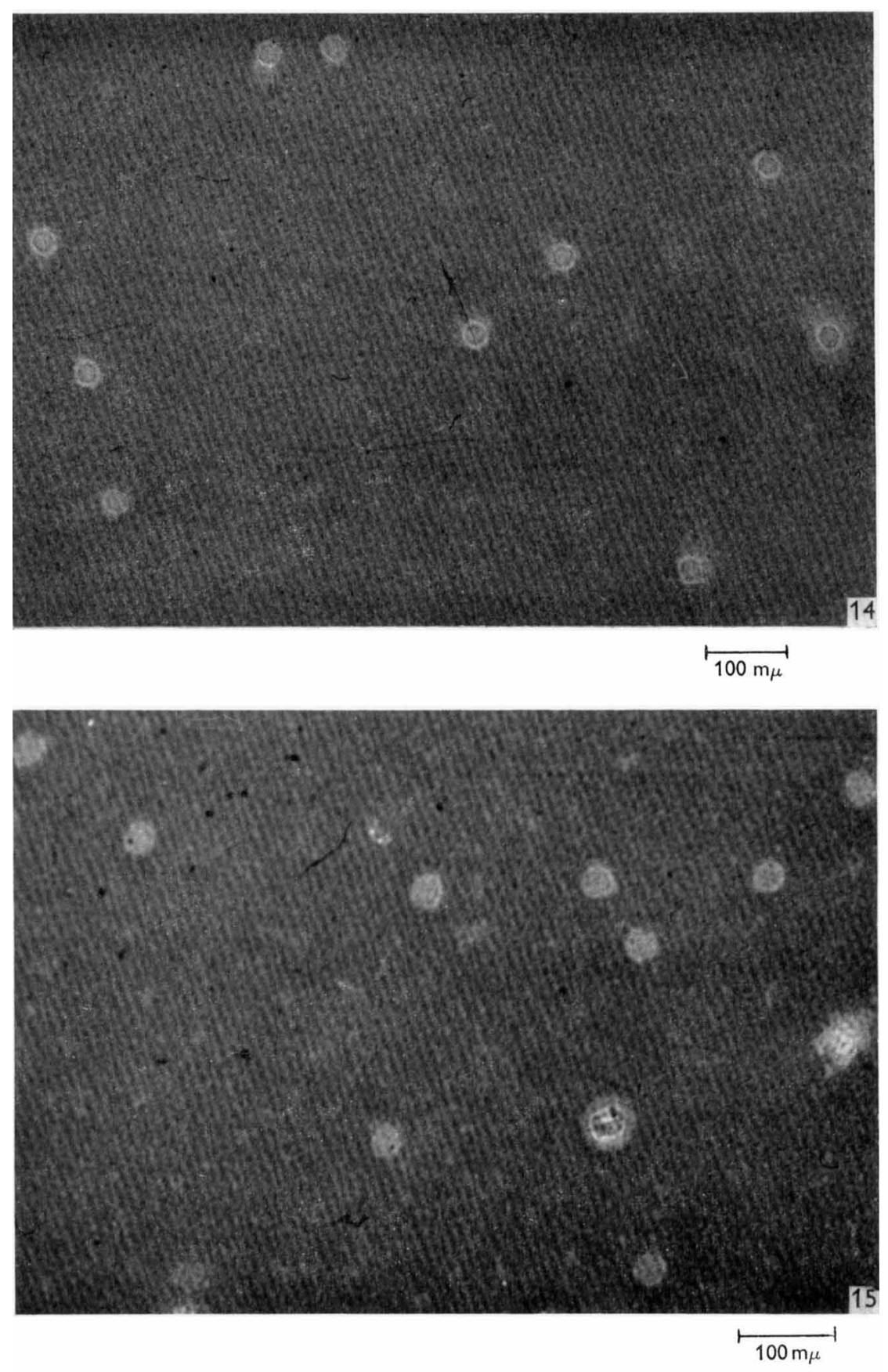

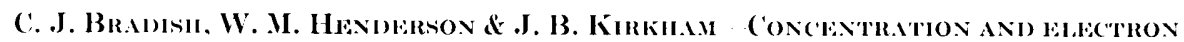
MICROSCOPY OF FMI) VIRES. PLATE 4 
Fig. 7. Virus of type Vallée $\mathrm{O} / \mathrm{H} .2$ from culture of bovine tongue epithelium, shadow cast with manganin.

Fig. 8. Virus of type Vallée $0 / 1$ from guinea-pig pad vesicular fluid, shadow cast with manganin.

Fig. 9. As fig. 2 but concentrated after incubation with $1 / 10$ heterotypic Asia 1 antiserum. Fig. 10. As fig. 2, but concentrate inactivated at $56^{\circ}$ for $15 \mathrm{~min}$.

\section{Plates 3 and 4}

Stained preparations of dilutions of virus concentrates containing about $10^{8}$ mouse ID 50/ $\mathrm{ml}$. Virus of type Vallée $\mathrm{O} / 1$ derived from guinea-pig pad vesicular fluid. Magnification to print $\times 100,000$ to $\times 130,000$ as indicated.

Figs. 11, 13. Stained by phosphotungstic acid in phosphate buffer.

Fig. 12. Stained by phosphomolybdic acid in phosphate buffer.

Fig. 14. Stained by uranyl acetate in ammonium carbonate buffer.

Fig. 15. Stained by phosphotungstic acid in phosphate buffer and freeze-dried.

(Received 24 September 1959) 